\title{
IS THE CURE WORSE THAN THE DISEASE? COUNTY-LEVEL EVIDENCE FROM THE COVID-19 PANDEMIC IN THE UNITED STATES
}

\author{
Catalina Amuedo-Dorantes \\ Neeraj Kaushal \\ Ashley N. Muchow \\ Working Paper 27759 \\ http://www.nber.org/papers/w27759
NATIONAL BUREAU OF ECONOMIC RESEARCH
1050 Massachusetts Avenue
Cambridge, MA 02138

August 2020

The views expressed herein are those of the authors and do not necessarily reflect the views of the National Bureau of Economic Research.

NBER working papers are circulated for discussion and comment purposes. They have not been peer-reviewed or been subject to the review by the NBER Board of Directors that accompanies official NBER publications.

(C) 2020 by Catalina Amuedo-Dorantes, Neeraj Kaushal, and Ashley N. Muchow. All rights reserved. Short sections of text, not to exceed two paragraphs, may be quoted without explicit permission provided that full credit, including $\odot$ notice, is given to the source. 
Is the Cure Worse than the Disease? County-Level Evidence from the COVID-19 Pandemic in the United States Catalina Amuedo-Dorantes, Neeraj Kaushal, and Ashley N. Muchow

NBER Working Paper No. 27759

August 2020

JEL No. I1,I12,I14

\section{ABSTRACT}

Using county-level data on COVID-19 mortality and infections, along with county-level information on the adoption of non-pharmaceutical interventions (NPIs) in the United States, we examine how the speed of NPI adoption affected COVID-19 mortality. Our estimates suggest that advancing the date of NPI adoption by one day lowers the COVID-19 death rate by 2.4 percent. This finding proves robust to alternative measures of NPI adoption speed, model specifications that control for testing and mobility, and across various samples: national, restricted to the Northeast region, excluding New York, and excluding the Northeast region. We also find that the adoption speed of NPIs is associated with lower infections, as well as lower non-COVID mortality, suggesting that these measures slowed contagion and the pace at which the healthcare system might have been overburdened by the pandemic. Finally, NPI adoption speed appears to have been less relevant in Republican counties, suggesting that political ideology might have compromised their efficiency.

Catalina Amuedo-Dorantes

5200 North Lake Rd. Merced

Merced, CA 5200

camuedo-dorantes@ucmerced.edu

Neeraj Kaushal

Columbia University

School of Social Work

1255 Amsterdam Avenue

New York, NY 10027

and NBER

nk464@columbia.edu
Ashley N. Muchow

1007 W. Harrison St., 4th floor BSB

Chicago, IL 60607

USA

anmuchow@gmail.com 


\section{Introduction}

The COVID-19 pandemic and the non-pharmaceutical interventions (NPIs) implemented in many countries to suppress the contagion have unsettled lives fundamentally and cratered the global economy. Epidemiologists contend that NPIs - such as safer-at-home orders, closures of non-essential businesses and schools, or bans on large gatherings-combined with testing, tracing, and isolating, are the only options to fight the pandemic until a vaccine is identified and made widely available or societies achieve herd immunity (Ferguson et al., 2006; Pichler et al., 2017; Tian et al., 2020). Yet, the intensity and vigor of NPI implementation have varied across countries, reflecting skepticism regarding their efficacy and concerns about their social and economic impacts.

In the United States, where COVID-19 has taken a high toll in terms of infections and mortality, skepticism toward NPIs reigns high among the public and legislators (Funk and Tyson, 2020). Early in the pandemic, President Trump famously criticized NPIs by remarking that "the cure cannot be worse than the problem itself." The nation remained divided on the effectiveness of NPIs, even as the pandemic raged from March to early May 2020 in the northeast, spreading to the rest of the country thereafter. Surveys show that conservative Republicans expressed more skepticism about NPIs than liberal Democrats (Funk and Tyson, 2020). State and local implementation and lifting of NPIs were often driven by political ideology. Republican-governed cities were slower in adopting NPIs, whereas cities led by Democrats were more aggressive (Willetts, 2020).

Amidst the highly partisan response to the pandemic, the question remains: has the timeliness of NPIs been effective in saving lives in the United States? Have these interventions helped reduce the spread of the virus? Has political ambivalence on NPIs influenced their 
effectiveness? The aim of this paper is to address these questions using county-level data on mortality, infections, and NPIs.

If NPIs have not been successful in the United States, that would mean the government has needlessly cratered the economy, compromised children's education, disrupted lives and livelihoods, and reduced the pace at which herd immunity can be achieved-ultimately validating public skepticism about these policies. Arguably, NPIs reduce the pace at which a population can acquire widespread immunity. For this reason, a number of countries, including the United Kingdom in the initial stages of the pandemic, and Sweden, opted against implementing NPIs. Additionally, the implementation of NPIs inevitably brings economies to a halt, resulting in tidal unemployment claims. Many countries and localities delayed their adoption and effective implementation to lessen their economic and social effects. These delays could have adversely affected the spread of the pandemic. Indeed, if NPIs are effective at reducing contagion, the politicization of NPIs can be blamed for the ambivalence and hesitation toward their implementation. This ambivalence and hesitation could explain the United States' failure to contain the virus, even as other developed countries have successfully reduced infections and mortality.

A couple of studies in the United States have investigated the effect of stay-at-home orders on infections and mortality from COVID-19 (Dave et. al. 2020; Fowler et al. 2020). ${ }^{1}$ Both studies find that NPIs are associated with lower infection and mortality rates. We build on this research by assessing the relevance of the adoption timing of two NPIs-safer-at-home orders and non-essential business closures-on mortality. Our research differs in that we

\footnotetext{
${ }^{1}$ There is growing international research on the effects of NPIs including Yun, Chen and Shi (2020) using Chinese data, Amuedo-Dorantes et al. (2020) using data from Spain, and Hsiang et al. (2020) and Imai et al. (2020) using cross-national data.
} 
specifically study the effect of NPI timeliness. To that end, we construct a measure that captures the relative speed of NPI adoption based on a county's rate of contagion when the NPI was adopted. $^{2}$

Further, we investigate whether NPI efficacy differed across counties with different political ideologies and different degrees of demographic, economic, and health-related vulnerabilities. To do the former, we construct a dummy to identify Republican counties, defined as counties where most residents voted for President Trump in the 2016 election, and estimate if NPI efficacy differed in those areas compared to other counties. For the latter, we use several pre-COVID county demographic, economic, and health characteristics to explore the differential efficacy of NPIs across counties with distinct degrees of vulnerability. Ideally, we would use data on COVID-19 mortality according to these traits, but such data are not available. Instead, we use pre-COVID county-level characteristics to explore differences in the relevance of NPI adoption timing across counties with different characteristics associated with poor COVID-19 health outcomes. Finally, we explore mechanisms through which NPI adoption speed might be critical, focusing on the spread of the infection and the ability to avert an overwhelmed health care system.

A challenge in estimating the causal effect of NPIs on mortality is that these interventions are adopted in response to the spread and severity of the virus. Because of the likely presence of reverse causality (i.e., COVID-linked deaths could be the cause behind the adoption of NPIs), a simple correlation between NPIs and COVID-linked mortality or infection will likely result in biased estimates, although they would likely be biased downwards. We address this by

\footnotetext{
${ }^{2}$ We follow Amuedo-Dorantes et al. (2020) who used a similar measure to study the effectiveness of NPIs in Spain and Correia et al. (2020) who studied the effect of NPIs during the 1918 Influenza.
} 
supplementing our primary analysis with an event study examining how COVID-19 death rates respond to NPI adoption.

Because of the ongoing nature of the pandemic, an additional challenge is the chosen temporal frame for our analysis. We focus on the early months of the pandemic, capturing when states and counties first adopted NPIs, through the first re-opening. This means we are comparing counties at various initial stages of the pandemic. To address this limitation, we estimate models that separate specific outliers during that period. Specifically, we experiment with: (i) restricting samples to Northeastern states that were the epicenter of the pandemic during our study period, (ii) excluding Northeastern states, and (iii) excluding New York. These sample modifications allow us to compare NPI speed between counties that experienced roughly similar stages of the pandemic during our study period.

Any research on the efficacy of NPIs in the United States is affected by the fact that data on reported infections and COVID-linked mortality are highly correlated with COVID-19 testing, which has varied across the country and over time. In counties with inadequate testing, reported infections likely underestimate actual infections and deaths attributable to COVID are likely to be reported as non-COVID mortalities. Further, if testing is correlated with NPIs, it will confound the estimates of the efficacy of NPIs. We address this by explicitly controlling for testing. Similarly, to address concerns regarding the possibility that the NPI estimates might be capturing any endogenous self-distancing potentially taking place prior to the adoption of an NPI, we include controls for the daily median maximum distance traveled by county residents as an estimate of mobility at the county level.

To explore the mechanisms at play, we examine how NPI adoption speed affects infections, and conduct state-level analyses of the association between NPIs and non-COVID 
deaths. Studies document that non-COVID deaths increased during the period of our study (Woolf et al. 2020). This could have occurred for various reasons, including the voluntary postponement of procedures or, in some instances, through an overwhelmed healthcare system. If timely adoption of the NPIs helped reduce the burden on the healthcare system, they should also lower non-COVID deaths.

We find that advancing the implementation date of NPIs by one day would have lowered the COVID-19 death rate by 2.4 percent. The finding proves robust to the use of alternative measures of NPI adoption speed, to controlling for testing and mobility, and to the removal of outliers_-such as New York and the Northeast region, from the analysis. We also find that the NPI adoption speed is associated with lower infections and lower non-COVID fatality, suggesting these measures operated both via slowing down the contagion and the burden of the pandemic on the healthcare system. We also find that the adoption speed of NPIs proves less critical in Republican counties, suggesting that the attitudes of the Republican leadership towards NPIs (e.g. social distancing, wearing masks, business closures) may have compromised their efficacy.

\section{Data}

\subsection{Mortality and Infections}

To determine how NPIs affected COVID-19 mortality in the United States, we use county-level data on COVID-19 deaths and infections collected by the Johns Hopkins University. This data includes information on the accumulated number of daily COVID-19 cases and deaths reported by state and local health departments (Dong, Du, and Gardner, 2020). ${ }^{3}$ We

\footnotetext{
${ }^{3}$ Retrieved on July 20, 2020 from https://github.com/CSSEGISandData/COVID-19. Using documentation provided by Johns Hopkins, we identified 34 counties that required consolidation to align with the level at which COVID-19
} 
use 2018 population figures from the American Community Survey to derive daily COVID-19 mortality rates by county.

We focus our analysis on the period from February 15, 2020 to April 23, 2020. While the first confirmed case of COVID-19 occurred in late January, country-wide contagion was reported starting in late February and early March. We lack information on the timing of reopenings by county. To avoid confounding the effects of NPI adoption speed with the continuation of NPI policies, we cap our study period at April 23, 2020, the day before the first NPI was lifted. ${ }^{4}$

We also collect information on state-level testing and overall mortality from the COVID Tracking Project and the Centers for Disease Control, respectively. Given that the identification of COVID-19 infections and attribution of causes of deaths are contingent upon detection, we use the most detailed information available from the COVID Tracking Project—daily test results by state- to account for variation in testing. ${ }^{5}$ We also collect information on mortality by cause of death from the Centers for Disease Control to estimate non-COVID deaths. ${ }^{6}$ We use the most detailed information available—weekly deaths by state-to explore some of the mechanisms responsible for our estimated impact of NPIs on COVID-19 mortality.

deaths were reported. This affected five counties in New York (New York City's five boroughs were originally grouped under New York county), two counties in Massachusetts (Dukes and Nantucket), Rhode Island's five counties, and 22 counties in Utah. In each of these instances, we aggregate population counts and apply population weights to estimate aggregated county characteristics for these consolidated areas, which in most cases, we collapse onto the most populous county. Cases and deaths that were not assigned to a particular geographic area are excluded from our analysis. These consolidations bring our county total to 3,117, down from 3,142.

${ }^{4}$ The state of Alaska lifted its safer-at-home and non-essential business closure orders on April 24, 2020.

${ }^{5}$ Retrieved on July 20, 2020 from https://covidtracking.com/data/download.

${ }^{6}$ Retrieved on July 20, 2020 from https://data.cdc.gov/NCHS/Weekly-counts-of-death-by-jurisdiction-and-causeo/u6jv-9ijr. 


\subsection{Non-Pharmaceutical Interventions}

We use data from the National Association of Counties (NACo) and Boston University’s School of Public Health to identify counties with NPIs in place during our study period. NACo compiles information on the type and timing of NPIs for every county in the United States. ${ }^{7}$ We complement this information with a comprehensive database assembled by Boston University researchers that records similar measures taken by states. ${ }^{8}$ We focus on two types of NPIs: nonessential business closures and safer-at-home policies.

While there is overlap between non-essential business closures and safer-at-home orders, business closure policies only restrict the activities of certain businesses, whereas safer-at-home orders include provisions that close non-essential businesses in addition to restricting individual movement. Safer-at-home policies_also referred to as "stay-at-home” and "shelter-in-place”explicitly restrict the movement and activities of individual residents unless they are engaged in “essential” activities. ${ }^{9}$ These policies prohibit residents from gathering or travelling outside of their homes unless for an essential activity and, as such, often consist of the closure of nonessential businesses (i.e., restaurants, bars, gyms). Though policies and enforcement vary, residents who ignore safer-at-home orders may face a misdemeanor punishable by fine, imprisonment or both (Harris, 2020).

\subsection{Mobility}

We make use of daily mobility data for each county obtained from Descartes Labs to carry out identification checks and account for variation in compliance with the social distancing

\footnotetext{
${ }^{7}$ Retrieved on July 20, 2020 from https://ce.naco.org/.

${ }^{8}$ Retrieved on July 20, 2020 from https://tinyurl.com/statepolicies.

${ }^{9}$ Activities and businesses deemed “essential” vary by county and state.
} 
imposed by the NPIs. ${ }^{10}$ Commercially available location data from smartphones and other mobile devices are used to sample the movement of individuals (Warren and Skillman, 2020). We use estimates of the median maximum distance traveled by residents to estimate daily mobility at the county level. These statistics are available for March 1, 2020 and beyond.

\subsection{County Characteristics}

To investigate whether NPI efficacy differed across counties with different political ideologies and different degrees of demographic, economic, and health-related vulnerabilities, we collect information on a series of county-level characteristics. We use information from the MIT Election Lab to capture county political affiliation, measured as the Republican vote share in the 2016 presidential election, which we use to identify Republican counties as those with a Republican vote share exceeding 50 percent. ${ }^{11}$ We collect information on a series of demographic and socioeconomic characteristics sourced from 2018 5-year American Community Survey estimates. Specifically, we compile estimates on the percent of county residents that are: (i) over the age of 65, (ii) without health insurance, (iii) unemployed, and (iv) living below the federal poverty line. Lastly, we use data from the Center for Medicaid and Medicare Service to measure county-level chronic disease prevalence. We use information from 2017, the latest year available, to create a comorbidity index that aggregates the percent of Medicare beneficiaries with chronic diseases associated with severe COVID-19 outcomes, including chronic lung disease (chronic obstructive pulmonary disease, asthma), heart conditions (atrial fibrillation, heart failure, Ischemic heart disease), cancer, hypertension, HIV/AIDS, diabetes, chronic kidney

\footnotetext{
${ }^{10}$ Retrieved on July 20, 2020 from https://github.com/descarteslabs/DL-COVID-19.

11 Retrieved on July 20, 2020 from https://dataverse.harvard.edu/dataverse/medsl_president; 28 counties were missing vote share information.
} 
disease, and liver disease (hepatitis). ${ }^{12}$ We standardize the index to have a mean of 0 and a standard deviation of 1 , with larger values indicating higher comorbidities.

\section{Methodology}

Our primary objective is to explore the effectiveness of NPIs on COVID-19 mortality. To that end, we start by estimating the following difference-in-differences model specification:

$$
Y_{c t}=\alpha+\beta\left(\text { Post }_{c t} \times N P I \text { speed }_{c}\right)+\rho_{c}+\vartheta_{t}+\varepsilon_{c t}
$$

where the vector $Y_{c t}$ represents the number of COVID deaths per 100,000 in county $c$ and date $t$.

We consider two different types of NPIs: safer-at-home policies and non-essential business closures. Our main regressor is an interaction term made up of two variables: (1) Post $_{c t}$, a dummy variable indicative of the period in county $c$ when the NPI was in effect; and (2) NPI speed ${ }_{c}$, the relative speed of NPI adoption based on county c's rate of contagion when the NPI was adopted. The post-NPI dummy (Post $\left.{ }_{c t}\right)$ includes a two-week delay to account for the average amount of time between infection and possible death (Lauer et al., 2020). The

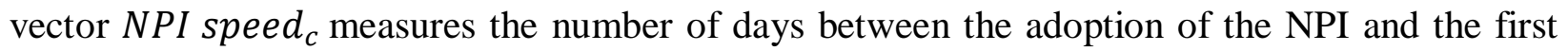
day-to-day doubling of county-level infections per capita. ${ }^{13}$ We multiply this count by minus one, so that higher values indicate a faster response. ${ }^{14}$ This operationalization allows us to gauge the impact of both the adoption of a particular NPI, as well as the effect of a faster response.

Equation (1) also includes daily fixed-effects to capture temporal shifts in the incidence and treatment of the disease across the country, and county fixed-effects to account for time-

\footnotetext{
${ }^{12}$ Retrieved from https://www.cms.gov/Research-Statistics-Data-and-Systems/Statistics-Trends-andReports/Chronic-Conditions/CC_Main. List of high-risk conditions made available by the CDC: https://www.cdc.gov/coronavirus/2019-ncov/hcp/underlying-conditions.html.

${ }^{13}$ We experiment with different contagion thresholds in robustness checks outlined later in the paper. Results prove consistent throughout.

${ }^{14}$ This approach aligns with that used in Correia et al. (2020).
} 
invariant differences potentially related to COVID mortality, such as population density, health infrastructure, and population comorbidities. Standard errors are clustered at the county level.

\section{Descriptive Evidence}

Our methodological approach is inspired in the daily variation in COVID-19 deaths and deaths per capita displayed in Figures 1 and 2, respectively. As shown therein, early- versus late-adopters of NPIs were seemingly impacted differently. We distinguish among three groups of counties: (1) early adopters, which include those with safer-at-home or business closure in place prior to the first day-to-day doubling of infections per capita; (2) late adopters, which include counties that adopted after the first day-to-day doubling; and (3) counties that never adopted a safer-at-home or business closure policy during our study period. COVID-19 deaths began to accelerate in mid-March for early and late adopters, but at notably different rates. Peak COVID-19 death rates in counties classified as late adopters were over 2.5 times as large as the peaks in early adopting counties. Also noteworthy is the relative dearth of COVID-19 mortality in the 311 counties that were not subject to an NPI during our study period. Most of these counties are located in sparsely populated states (i.e., North and South Dakota, Nebraska, and Wyoming).

Figure 3 illustrates the staggered adoption of safer-at-home and business closure policies, which provides the temporal and geographic variation needed for identification. The first NPI was adopted by the state of California on March 16, 2020. By March 20, a total of 134 counties, including California's 58, had an NPI in place. As illustrated in the subsequent maps, most NPI adoptions occurred in late-March and early-April. By March 30, a total of 1,979 counties were subject to a safer-at-home, business closure order, or both. This number grew to 2,806 by April 6-after which, no additional NPIs were implemented during the period covered in this study. 
Table 1 displays basic descriptive statistics for the full sample, and by NPI adoption timing for the 3,117 counties included in our sample. Counties were observed daily from February 15 April 23, 2020 (69 days). The descriptive statistics confirm the trends illustrated in the figures. COVID-19 infections and mortality were lower in early-adopting counties when compared to counties adopting NPI measures late, despite the larger number of tests performed in the latter group. Counties that never adopted the measures were the smallest in size and had COVID-19 infections and mortality figures that were well below those of late and early NPI adopters. There are other differences worth noting across counties. For instance, counties that were early NPI adopters were somewhat between non-adopters and late adopters in terms of size. In terms of pre-COVID characteristics, the early adopters had higher mobility indexes, a larger share of elderly and people living in poverty, and were more likely to be classified as

Republican. In contrast, late NPI adopting counties were, by far, the largest in size and had higher comorbidity indexes. However, differences in unemployment rates and health insurance were not large across counties that adopted NPIs early, late, or never.

\section{Main Findings and Robustness Checks}

Our main objective is to learn about the importance of timing when adopting NPIs in fighting COVID-19 mortality. If timing proves critical, a secondary objective is to gain a better understanding of the channels enabling the effectiveness of the NPI in curtailing deaths-an investigation that involves uncovering heterogenous impacts of the adopted NPIs.

To achieve our main aim, we start by estimating several model specifications of equation (1). Initially, we simply consider the adoption timing of either business closures or stay-at-home orders - the most common NPIs during the COVID-19 pandemic. The results from this exercise are displayed in Table 2. The baseline specification only includes date and county fixed effects. 
Subsequently, we control for the level of testing in the state, as well as mobility measured as the median maximum distance traveled by county residents. COVID testing was inadequate in the initial months after the outbreak and began to improve over our study period. Controlling for testing allows us to account for any mechanical association between testing, infections, NPIs, and COVID mortality. ${ }^{15}$ Accounting for mobility allows us to capture the role played by any endogenous self-distancing irrespective of whether the NPIs were in place. Regardless of the model specification used, the speed of adoption of NPIs significantly curtails COVID-19 deaths. Based on the estimates from the most complete model specification, we find that moving up the implementation date of any of the NPIs (if both were adopted, whichever came first) by one day lowers the COVID-19 death rate by 2.4 percent. ${ }^{16}$

o gain a better understanding of which of the two most common NPIs matters the most, we re-estimate the models including separate measures of adoption speed for each NPI. As can be seen in Table 3, both measures seem to help curtail deaths. Adopting business closures oneday earlier lowers COVID-19 deaths by 1.5 percent and, similarly, moving up the adoption of a stay-at-home order by one day would curtail the COVID-19 mortality rate by 1.2 percent. ${ }^{17}$

Finally, in Table 4, we conduct several robustness checks to assess the sensitivity of our findings to: (1) alternative measures of the NPI adoption speed; (2) the application of population weights to derive nationally representative estimates; and (3) using different samples that exclude New York and the Northeast region (Connecticut, Maine, Massachusetts, New Hampshire, Rhode Island, Vermont, New Jersey, New York, and Pennsylvania) as potential

\footnotetext{
${ }^{15}$ We would have preferred to control for county-level testing but those data are not available to us.

${ }^{16}$ Computed as: $(\beta * \Delta X) * 100 / \mu_{D V}$, where: $\Delta X=1$ and $\mu_{D V}=0.101$.

${ }^{17}$ The effects of these two NPIs are not statistically different from one another: $\mathrm{F}(1,2619)=1.02, p=0.313$.
} 
outliers during the period under analysis, or look at the Northeast region separately. In what follows, we briefly refer to each robustness check.

As noted earlier, the estimates in Table 2 use a contagion threshold equal to the first dayto-day doubling of infections per capita in each county. In columns (1) and (2) of Table 4, we experiment with different contagion thresholds: the first day infections per capita exceeded the national average from January 21, 2020 to March 7, 2020 (column 1), and the first day infections per capita exceeded the county average prior to any NPI adoption (column 2). ${ }^{18}$ Our results prove robust to the use of these alternative contagion thresholds. Accelerating the adoption speed of the NPIs by one day lowers the COVID-19 mortality rate by 2 percent in column (1), and by 4.4 percent in column (2).

Next, we experiment with using population weights to derive nationally representative estimates. As can be seen in column (3) of Table 4, we continue to find that speeding up the adoption of the NPIs by one day would have significantly lowered mortality from COVID-19. In this case by 4.6 percent, as opposed to 2.4 percent using the unweighted estimates of Table 2.

Finally, we test the sensitivity of our findings across different geographic samples. First, we exclude New York, which was the epicenter of the pandemic during the period under consideration, to check if our results were driven by its presence in the sample. As can be seen in column (4) of Table 4, the results are somewhat lower, but remain robust to this exclusion. Speeding up NPI adoption by one day would have lowered the COVID-19 mortality rate by 2.2 percent. We next experiment with excluding the entire Northeast region of the country (column 5), as well as with focusing entirely on that region (column 6). As shown therein, the results confirm our prior findings, underscoring the significance of NPIs in lowering mortality in the

\footnotetext{
${ }^{18}$ National infection rates between January 1 and March 7, 2020 averaged 7.30 infections per 100,000. The pre-NPI county average infection rate was 1.83 infections per 100,000.
} 
Northeast. Specifically, speeding up the implementation of the NPIs by one day would have lowered COVID-19 deaths by approximately 2 percent if we exclude the entire Northeast region. However, in that region alone, deaths from COVID-19 would have dropped by 7.6 percent.

In sum, the analyses in Table 4 confirm the robustness of our estimates presented Table 2 to alternative definitions of a contagion outbreak, to the use of population weights, and to changes to the geographic scope of our sample. ${ }^{19}$

\section{Identification}

An important caveat of the difference-in-difference approach adopted above refers to the non-random adoption of NPIs. Given their implicit economic cost, counties are likely reticent to impose social distancing, unless it is suspected that the health care system will be overwhelmed as the death toll climbs. Luckily, from an inferential standpoint, if NPIs are implemented once contagion has surpassed a threshold, the estimated impact of NPIs in curtailing COVID-related deaths would likely represent a lower bound estimate of the true effectiveness of the adopted measures if they were adopted in a timely manner. A related concern refers to endogeneity biases stemming from unobserved heterogeneity. For instance, if the adoption of an NPI is related to unobserved or unaccounted for factors, such as the county's political ideology, which may affect timely adoption of NPIs as well as cause laxity in the adoption of other measures, including use of face masks or social distancing (Dave et al., 2020), the estimated impact of NPIs might confound the impact of other unobserved factors.

\footnotetext{
${ }^{19}$ This is also true if we distinguish between business closures and stay-at-home orders, as shown in Table A in the appendix.
} 
To address these endogeneity concerns, we conduct an event study. The latter allows us to gauge if COVID-19 mortality trends already systematically differed across counties that adopted NPIs earlier versus later, prior to the adoption of any NPI. In this manner, we address concerns regarding pre-existing differential pre-trends across early- versus late-adopting counties. Secondly, we are able to gauge if there is a clear break in the trend of COVID-19 mortality following the adoption of the NPIs. This enables us to dissipate concerns regarding the confounding impact of unobserved and unaccounted for factors. Finally, we can examine the dynamic impact of NPIs and assess if it makes sense based on how these policies reduce infections and deaths. Specifically, we estimate the following model:

$$
Y_{c t}=\alpha+\sum_{-35}^{35} \beta_{t} \text { Post }_{c t}+\rho_{c}+\vartheta_{t}+\varepsilon_{c t}
$$

Equation (2) differs from equation (1) in that it includes leads and lags to the NPI adoption timing, allowing us to examine the existence of pre-trends up to 35 days prior, as well as dummies for up to 35 days after NPI adoption to learn about the impact of the implemented policies. Figure 4 displays the coefficients from the event study corresponding to the most complete model specification used in Table 2, along with 95 percent confidence intervals. All estimates for the days preceding the adoption of the first NPI in the county are close to zero, strongly supporting the assumption of no pre-trends. In addition, there is a clear break in the trend in COVID-19 deaths approximately 4 weeks later-a common turn around period from infection to recovery of most mild cases (Britt, 2020), staying down thereafter.

Another concern regarding identification refers to the start of social distancing, as well as the observance of business closures and stay-at-home orders. If residents in early-adopting counties were already practicing self-distancing prior to the adoption of an NPI, its estimated effectiveness in curtailing deaths would be biased upwards. (The opposite would be the case if, 
instead, that was predominantly the case among residents in counties that were late adopters of NPIs - namely, the estimated impact of the NPI would be biased downwards). In addition, it is important for the orders to have been observed by the public similarly across counties. If orders were observed differentially in counties that were early- versus late-adopters, the estimated impact of the NPI could also be biased. Fortunately, both concerns have been addressed by recent research (e.g., Alexander and Karger, 2020) showing that county-level measures of mobility declined sharply the day after stay-at-home orders went into effect, but not prior to their implementation. Furthermore, the authors find that responses to stay-at-home orders were uniform across the country, and did not vary by income, political leanings, or urban/rural status. Those findings reinforce the notion of no obvious self-distancing taking place prior to the adoption of NPIs, as well as the obedient response to the mandated orders.

\section{Mechanisms}

According to the Centers for Disease Control and Prevention, the COVID-19 virus is primarily transmitted between people through respiratory droplets emitted during coughing or sneezing and through fomites in the environment around the infected person. ${ }^{20}$ By reducing close contact between individuals, the adoption of NPIs, such as business closures and stay-athome orders, may slow down the COVID-19 virus transmission and, therefore, deaths. In the absence of vaccines and reliable tracking systems, NPIs have also been invoked to flatten the pandemic curve by lowering the demands on public healthcare services, allowing for COVID-19 patients to be properly treated (Ferguson et al., 2020). As such, NPIs could have helped lower COVID-19 mortality directly by reducing contagion, as well as indirectly by preventing bottlenecks in the healthcare system.

\footnotetext{
${ }^{20}$ See: https://www.cdc.gov/coronavirus/2019-ncov/faq.html\#Spread.
} 
As an attempt to sort out these two channels, we look first at COVID-19 infections. If the effectiveness of the NPIs did not stem from reducing contagion but, rather, from avoiding an overwhelmed healthcare system, we should not necessarily observe a reduction in the infection rate. Yet, as displayed in columns (1) through (3) of Table 5, adopting one of the two types of NPIs under examination one day earlier would have lowered infections by roughly 2 percent, regardless of whether we use all counties, exclude New York or the entire Northeast region.

We then look at how the early versus late adoption of NPIs might have affected nonCOVID mortality. If NPIs primarily helped curtail pandemic deaths by preventing the healthcare system from becoming overwhelmed, non-COVID mortality rates should also be lower in those regions where the NPIs were adopted earlier, as non-COVID patients could still be treated. Based on the results in columns (3) through (6) in Table 5, while negative, the estimated coefficients are either marginally significant at the 10 percent level or not statistically different from zero. In other words, the response speed does not significantly alter non-COVID deaths, as one would expect if preventing congestion of the healthcare system was a primary channel for the reduction in COVID-19 mortality following NPI adoption. Thus, our estimates suggest that excess deaths from non-COVID causes observed in other studies (e.g. Woolf et al. 2020) during the period of our study were not the by-product of the adoption speed of NPIs.

In sum, the results in Table 5 point to NPIs effectively reducing COVID-19 mortality by curtailing contagion and the spread of the virus. These findings prove robust when we further distinguish between business closures and stay-at-home orders, as displayed in Table B of the appendix.

\section{Heterogeneous Impacts}


To conclude, we examine if the relative adoption speed of NPIs impacted counties differently based on other traits associated with either their adoption, or with the uneven impact of the disease. Studies show that attitudes towards the efficacy of NPIs have been partisan, with Republican governors and mayors being more reluctant to implement NPIs. It is also possible that residents in majority-Republican counties with NPIs in place may be less compliant with health care guidelines and recommendations. In Table 6, we first examine the differential impact that the speed of NPI adoption had in Republican counties-measured as those with a Republican vote share above 50 percent in the 2016 presidential election-given the role of political partisan ideology in NPI adoption (Dave et al., 2020; Gupta et al., 2020). As can be seen in column (1), adopting an NPI one day earlier lowers COVID-19 mortality in majorityRepublican counties by approximately 2.4 percent, whereas the reduction in other counties reaches 5.4 percent. In other words, speeding up the implementation of NPIs in primarily Republican counties would lower COVID-19 mortality by half the amount it would in nonRepublican counties. Why? Perhaps, NPIs are less strictly observed in Republican counties, in which case, speeding up their implementation does not have the same bite as in other counties. Note that descriptive statistics in Table 1 show that, according to our NPI speed measure, Republican counties were more likely to be early adopters, largely on account of the late outbreak of the pandemic in these counties. Thus, our findings suggest that, despite the advantage of learning from the experience of counties where the virus spread earlier, the NPIs were less effective in these counties.

Finally, we consider how the NPI effectiveness might have varied according to various county-level traits known to be correlated to COVID-19 mortality due to the high-incidence of the disease among the elderly and individuals with poor health. To that end, we first explore if 
the adoption speed of NPIs particularly benefits localities with a higher share of individuals age 65 and older. As shown in column (2) of Table 6, we do not find that to be the case, although the differential impact is only marginally statistically different from zero. This could possibly be because most COVID-related elderly fatalities were in nursing homes, where the two NPIs we are investigating might not have been as effective in reducing contagion. Residents of nursing homes would require other measures limiting their potential exposure to the virus, such as restrictions of visitors or the safe distancing of residents from each other.

We then repeat the same exercise using other county-level traits reflective of the share of the population that lack health insurance, are unemployed, or live below the federal poverty line. We also look at the differential impact that speeding up the implementation of NPIs might have in counties with higher comorbidity indexes. As shown in columns (3) through (6) in Table 6, speeding up the implementation of NPIs does not appear to affect the death rate for COVID-19

any differently in counties with higher versus lower values of the abovementioned traits. To some degree, this is not surprising given the aggregated nature of those traits. As such, the nonsignificance of those demographic traits should be interpreted with caution.

\section{Summary and Conclusions}

The rapid spread of the COVID-19 pandemic took the world by surprise. In the absence of a vaccine, and to halt the devastating impact of the pandemic on lives, several countries opted for the adoption of non-pharmaceutical interventions (NPIs). The United States was no different in that regard, even though the response has been more fragmented and piecemeal. Prior research has shown the effectiveness of NPIs in curtailing deaths in the United States, Europe and Asia. Our focus is on the importance of their timeliness, the mechanisms behind it, and the 
heterogeneity of any effectiveness depending on the political ideology and degree of vulnerability of counties.

Using county-level data on COVID-19 mortality and infections, along with county-level information on the adoption of stay-at-home orders and business closures, we examine how the adoption speed of NPIs has affected COVID-19 mortality. We find that moving up the implementation date of NPIs by one day lowers the COVID-19 death rate by 2.4 percent. The effectiveness of acting early is similar for both stay-at-home orders and business closures. An event study addresses concerns regarding the endogeneity of NPI adoption, and robustness checks show the results persist when introducing controls for testing and mobility, altering the definition of adoption speed, weighting counties by population size, and considering different geographic scopes. Finally, we confirm how the relevance of responding early stems from the ability to slow contagion, which likely prevented the overburdening of the healthcare system. We also find that NPI adoption speed has less relevance in Republican counties—a possible byproduct of skepticism and reluctance to apply or fully comply with NPIs. In contrast, NPIs appear similarly effective, and their speed of implementation equally as relevant, in counties with distinct degrees of vulnerability to the disease, as captured by an index of comorbidity and the share of residents without health insurance, unemployed, or living in poverty.

While we await anxiously a vaccine or cure, NPIs remain the main mechanism to curtail COVID-19 deaths. Gaining a better understanding of their timeliness and the importance of responding early is essential, especially in the foreseeable occurrence of additional waves. 


\section{References}

Alexander, Diane and Ezra Karger. 2020. "Do Stay-at-Home Orders Cause People to Stay at Home? Effects of Stay-at-Home Orders on Consumer Behavior. Federal Reserve Bank of Chicago Working Paper, No. 2020-12. At: https://www.chicagofed.org/publications/workingpapers/2020/2020-12

Amuedo-Dorantes, Catalina, Cristina Borra, Noelia Rivera Garrido, Almudena Sevilla. 2020. “Timing is Everything when Fighting a Pandemic: COVID-19 Mortality in Spain”, IZA DP No. 13316.

Bootsma, Martin C. J., and Neil M. Ferguson. 2007. "The Effect of Public Health Measures on the 1918 Influenza Pandemic in U.S. Cities”, PNAS, 104(18): 7588-7593.

Britt, Robert Roy. 2020. "From Infection to Recovery: How Long it Lasts". Available at: https://elemental.medium.com/from-infection-to-recovery-how-long-it-lasts-199e266fd018

Bullard, Robert. 2005. “All Transit is not Created Equal." Moving the Movement for Transportation Justice, Vol. 12 No. 1, Winter.

Correia, Sergio, Stephan Luck, and Emil Verner. 2020. "Pandemics Depress the Economy, Public Health Interventions Do Not: Evidence from the 1918 Flu”, March 30. Federal Reserve Bank of New York. Mimeo.

Dave, Dhaval, Andrew I. Friedson, Kyutaro Matsuzawa, and Joseph J. Sabia. 2020. "When Do Shelter-In-Place Orders Fight COVID-19 Best? Policy Heterogeneity across States and Adoption Time”. IZA DP No. 13190.

Dong, E., Du, H., \& Gardner, L. 2020. “An interactive web-based dashboard to track COVID-19 in real time.” The Lancet Infectious Diseases, 20(5), 533-534.

Ferguson, N., Laydon, D., Nedjati-Gilani, G., Imai, N., Ainslie, K., Baguelin, M., ... Dighe, A. (2020). "Report 9 - Impact of non-pharmaceutical interventions (NPIs) to reduce COVID-19 mortality and healthcare demand”, Faculty of Medicine, Imperial College London.

Flaxman, Seth, Swapnil Mishra, Axel Gandy et al. 2020. "Estimating the number of infections and the impact of nonpharmaceutical interventions on COVID-19 in 11 European countries”. Imperial College London.

Fowler, James H., Seth J. Hill, Remy Levin, and Nick Obradovich. 2020. "The Effect of Stay-atHome Orders on COVID-19 Infections in the United States”. Mimeo.

Funk, Carry and Alec Tyson, 2020. "Partisan Differences Over the Pandemic Response Are Growing,” Scientific American, Opinion.

Gelatt, Julia. 2020 Revised. Immigrant Workers: Vital to the U.S. COVID-19 Response, Disproportionally Vulnerable. Washington, DC: Migration Policy Institute. 
Guimbeau, Amanda, Nidhiya Menon, and Aldo Musacchio. 2020. “The Brazilian Bombshell? The Long-Term Impact of the 1918 Influenza Pandemic the South American Way”. NBER Working Paper No. 26929.

Gupta, S., Nguyen, T., Rojas, F. L., Raman, S., Lee, B., Bento, A., ... Wing, C. (2020). "Tracking Public and Private Responses to the COVID-19 Epidemic: Evidence from State and Local Government Actions.” Cambridge, MA. https://doi.org/10.3386/w27027

Harris, Jonathan. 2020. What is a "Safer at Home" Policy? Washington, DC: National Association of Counties.

Hsiang, S., Allen, D., Annan-Phan, S. et al. 2020. "The effect of large-scale anti-contagion policies on the COVID-19 pandemic.” Nature, https://doi.org/10.1038/s41586-020-2404-8

Hutchins, Sonja S., Kevin Fiscella, Robert S. Levine, Danielle C. Ompad, and Marian McDonald. 2009. "Protection of Racial/Ethnic Minority Populations During an Influenza Pandemic.” American Journal of Public Health 99, S261_S270.

N. Imai, I. Dorigatti, A. Cori, S. Riley, N.M. Ferguson. 2020. "Estimating the potential total number of novel Coronavirus (2019-nCoV) cases in Wuhan City.”

Kermack, William O., and Anderson G. McKendrick. 1927. "A Contribution to the Mathematical Theory of Epidemics." Proceedings of the Royal Society of London A, 115, 700721.

Lauer, S. A., Grantz, K. H., Bi, Q., Jones, F. K., Zheng, Q., Meredith, H. R., ... Lessler, J. 2020. "The incubation period of coronavirus disease 2019 (COVID-19) from publicly reported confirmed cases: estimation and application.” Annals of Internal Medicine, 172(9), 577-582.

Markel, Howard, Harvey B. Lipman, J. Alexander Navarro, Alexandra Sloan, Joseph R. Michalsen, Alexandra Minna Stern, and Martin S. Cetron. 2007. "Nonpharmaceutical Interventions Implemented by US Cities During the 1918-1919 Influenza Pandemic”. JAMA, 298 (19).

Økland, H.; Mamelund, S.-E. 2019. "Race and 1918 Influenza Pandemic in the United States: A Review of the Literature.” Int. J. Environ. Res. Public Health, 16, 2487.

Qiu, Yun, Xi Chen and Wei Shi. 2020. "Impacts of Social and Economic Factors on the Transmission of Coronavirus Disease 2019 (COVID-19) in China.” Forthcoming in the Journal of Population Economics.

Semega, J., M. Kollar, J, Creamer and A, Mohanty. 2019. Income and Poverty in the United States: 2018. US census Bureau.

Warren, M. S., \& Skillman, S. W. 2020. "Mobility changes in response to COVID-19.” ArXiv Preprint ArXiv:2003.14228. 
Willetts, M. 2020. "In Some GOP-led States, 'Blue' Cities Lead the Charge for Coronavirus Restrictions.” The State, March 31. At:

www.thestate.com/news/coronavirus/article241662566.html

Woolf, Steven ; Derek A. Chapman, Roy T. Sabo, Daniel M. Weinberger; Latoya Hill. 2020. “Excess Deaths From COVID-19 and Other Causes, March-April 2020.” Research Letter, JAMA, 324(5):510-513.

Yancy, Clyde W. 2020. “COVID-19 and African Americans”. JAMA.

Yun Qiu, Xi Chen, Wei Shi. 2020. "Impacts of social and economic factors on the transmission of coronavirus disease (COVID-19) in China.” Mimeo. 
Table 1: Descriptive Statistics

\begin{tabular}{|c|c|c|c|c|c|c|c|c|}
\hline \multirow{3}{*}{$\begin{array}{l}\text { Sample } \\
\text { Variable } \\
\end{array}$} & \multirow{2}{*}{\multicolumn{2}{|c|}{ Overall }} & \multicolumn{6}{|c|}{ By NPI Adoption Timing } \\
\hline & & & \multicolumn{2}{|c|}{ Early Adopters } & \multicolumn{2}{|c|}{ Late Adopters } & \multicolumn{2}{|c|}{ Never Adopters } \\
\hline & Mean & S.D. & Mean & S.D. & Mean & S.D. & Mean & S.D. \\
\hline COVID deaths per 100,000 & 0.071 & 0.775 & 0.058 & 0.740 & $0.208 *$ & 1.148 & $0.015^{*}$ & 0.412 \\
\hline COVID infections per 100,000 & 1.651 & 11.789 & 1.369 & 10.536 & $4.085^{*}$ & 12.567 & $1.109 *$ & 18.177 \\
\hline Population & 105,092 & 359,144 & 62,388 & 240,979 & $472,103^{*}$ & 760,835 & $25,342^{*}$ & 63,760 \\
\hline NPI speed & 30.809 & 39.917 & 36.120 & 39.951 & $-6.096 *$ & 4.081 & NA & NA \\
\hline Safer-at-home speed & 25.901 & 38.000 & 31.590 & 38.303 & $-7.236^{*}$ & 4.765 & NA & NA \\
\hline State test results per 100,000 & 285.929 & 459.723 & 277.767 & 446.872 & $326.315^{*}$ & 543.979 & $304.474 *$ & 452.274 \\
\hline Mobility index & 6.121 & 15.269 & 6.475 & 16.881 & $4.239 *$ & 3.972 & $5.788^{*}$ & 6.542 \\
\hline Majority Republican (2016) & 0.806 & 0.396 & 0.835 & 0.371 & $0.494^{*}$ & 0.500 & $0.932 *$ & 0.251 \\
\hline Percent over age 65 (2018) & 18.380 & 4.586 & 18.626 & 4.343 & $15.626^{*}$ & 4.856 & $19.569 *$ & 4.976 \\
\hline Percent without health insurance (2018) & 8.208 & 3.993 & 8.268 & 4.053 & 8.573 & 3.494 & $7.320 *$ & 3.926 \\
\hline Percent unemployed (2018) & 1.218 & 0.587 & 1.259 & 0.583 & $1.326^{*}$ & 0.447 & $0.768 *$ & 0.560 \\
\hline Percent living below FPL (2018) & 10.741 & 4.173 & 10.983 & 4.134 & $9.923^{*}$ & 3.854 & $9.762 *$ & 4.550 \\
\hline Comorbidity index (2017) & 0.000 & 1.000 & 0.055 & 1.014 & 0.123 & 0.858 & $-0.573 *$ & 0.842 \\
\hline
\end{tabular}

Notes: Statistics are reported at the county-level unless otherwise specified. These estimates are not weighted by population. Counties that never adopted an

NPI during our study period were assigned an uninformative NPI speed value to ensure these cases were preserved when estimating the model outlined in Eq. 1.

Our specification interacts NPI speed with a dummy indicative of the day a county adopted an NPI-effectively rendering this value zero for never adopters.

${ }^{*} \mathrm{p}<.05$ in t-test comparing value with Early Adopters. 
Table 2: Impact of NPI Speed on COVID-19 Deaths per 100,000 Residents

\begin{tabular}{lccc}
\hline Model Specification & $\mathbf{( 1 )}$ & $\mathbf{( 2 )}$ & $\mathbf{( 3 )}$ \\
\hline Post $_{c t} \times$ NPI speed & & $-0.0021^{* * *}$ & $-0.0024^{* * *}$ \\
& $-0.0019^{* * *}$ & $(0.0002)$ & $(0.0002)$ \\
State test results per 100,000 & $(0.0002)$ & $0.0003^{* * *}$ & $0.0003^{* * *}$ \\
& & $(0.0000)$ & $(0.0000)$ \\
Mobility & & & -0.000001 \\
& & & $(0.0001)$ \\
Date Fixed-Effects & & $\mathrm{Y}$ & $\mathrm{Y}$ \\
County Fixed-Effects & $\mathrm{Y}$ & $\mathrm{Y}$ & $\mathrm{Y}$ \\
& & & 141,480 \\
Observations & 215,073 & 215,073 & 0.132 \\
R-squared & 0.087 & 0.092 & 0.101 \\
Dependent Variable Mean & 0.071 & 0.071 & \\
\hline
\end{tabular}

Notes: $* * * \mathrm{p}<0.01, * * \mathrm{p}<0.05, * \mathrm{p}<0.1$. All regressions include a constant term. Standard errors are in parentheses and clustered at the county level. This table reports the estimates from Equation (1) using daily COVID-19 deaths occurring between February 15, 2020 to April 23, 2020. The specification in column (1) only includes date and county fixed effects. Column (2) controls for state-level testing and Column (3) further controls for residential mobility. Mobility data was not available for the period before March 1; the estimates reported in Column (3) use daily COVID-19 deaths for 2,260 counties with mobility data for the period spanning from March 1, 2020 to April 23, 2020. We re-estimated the models presented in columns (1) and (2) using this restricted sample. While our estimates attenuate slightly, substantively, they do not change (see Panel A of Table C in the appendix). 
Table 3: Impact of Disaggregated NPI Speeds on COVID-19 Deaths per 100,000 Residents

\begin{tabular}{|c|c|c|c|}
\hline Model Specification & (1) & (2) & (3) \\
\hline 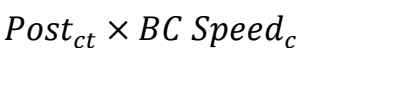 & $\begin{array}{c}-0.0016 * * * \\
(0.0002)\end{array}$ & $\begin{array}{c}-0.0012 * * * \\
(0.0002)\end{array}$ & $\begin{array}{c}-0.0015^{* * *} \\
(0.0002)\end{array}$ \\
\hline Post $_{c t} \times$ SAH Speed $_{c}$ & $\begin{array}{c}-0.0008 * * * \\
(0.0002)\end{array}$ & $\begin{array}{c}-0.0011^{* * *} \\
(0.0002)\end{array}$ & $\begin{array}{c}-0.0012 * * * \\
(0.0002)\end{array}$ \\
\hline State test results per 100,000 & & $\begin{array}{c}0.0003^{* * *} \\
(0.0000)\end{array}$ & $\begin{array}{c}0.0003^{* * *} \\
(0.0000)\end{array}$ \\
\hline Mobility & & & $\begin{array}{c}-0.000002 \\
(0.0001)\end{array}$ \\
\hline Date Fixed-Effects & Y & Y & $\mathrm{Y}$ \\
\hline County Fixed-Effects & $\mathrm{Y}$ & $\mathrm{Y}$ & $\mathrm{Y}$ \\
\hline Observations & 215,073 & 215,073 & 141,480 \\
\hline R-squared & 0.087 & 0.092 & 0.132 \\
\hline Dependent Variable Mean & 0.071 & 0.071 & 0.101 \\
\hline
\end{tabular}

Notes: $* * * \mathrm{p}<0.01, * * \mathrm{p}<0.05, * \mathrm{p}<0.1$. All regressions include a constant term. Standard errors are in parentheses and clustered at the county level. This table reports the estimates from Equation (1) using daily COVID-19 deaths occurring between February 15, 2020 to April 23, 2020. The specification in column (1) only includes date and county fixed effects. Column (2) controls for state-level testing and Column (3) further controls for residential mobility. Mobility data was not available for the period before March 1; the estimates reported in Column (3) use daily COVID-19 deaths for 2,260 counties with mobility data for the period spanning from March 1, 2020 to April 23, 2020. We re-estimated the models presented in columns (1) and (2) using this restricted sample. While our estimates attenuate slightly, substantively, they do not change (see Panel B of Table C in the appendix). 
Table 4: Robustness Checks - Impact of NPI Speed on COVID-19 Deaths per 100,000 Residents

\begin{tabular}{|c|c|c|c|c|c|c|}
\hline \multirow{2}{*}{$\begin{array}{l}\text { Robustness Check } \\
\text { Column }\end{array}$} & \multicolumn{2}{|c|}{ Alternative Contagion Threshold } & \multirow{2}{*}{$\begin{array}{c}\text { Alternative Weighting } \\
\text { (3) }\end{array}$} & \multicolumn{3}{|c|}{ Alternative Samples } \\
\hline & (1) & (2) & & (4) & 5) & (6) \\
\hline Model Specification & $\begin{array}{c}\text { Pre-NPI National } \\
\text { Average } \\
\end{array}$ & $\begin{array}{c}\text { Pre-NPI County } \\
\text { Average } \\
\end{array}$ & Population weighted & Excluding NY & $\begin{array}{c}\text { Excluding } \\
\text { NE Region }\end{array}$ & $\begin{array}{c}\text { Only the } \\
\text { NE Region }\end{array}$ \\
\hline Post $_{c t} \times N P I$ speed $_{c}$ & $\begin{array}{c}-0.0014^{* * *} \\
(0.0002)\end{array}$ & $\begin{array}{c}-0.0038 * * * \\
(0.0003)\end{array}$ & $\begin{array}{c}-0.0161 * * \\
(0.0078)\end{array}$ & $\begin{array}{c}-0.0017 * * * \\
(0.0002)\end{array}$ & $\begin{array}{c}-0.0013 * * * \\
(0.0002)\end{array}$ & $\begin{array}{c}-0.0166 * * * \\
(0.0034)\end{array}$ \\
\hline Date Fixed-Effects & $\mathrm{Y}$ & $\mathrm{Y}$ & $\mathrm{Y}$ & $\mathrm{Y}$ & $\mathrm{Y}$ & $\mathrm{Y}$ \\
\hline County Fixed-Effects & $\mathrm{Y}$ & $\mathrm{Y}$ & $\mathrm{Y}$ & $\mathrm{Y}$ & $\mathrm{Y}$ & $\mathrm{Y}$ \\
\hline Observations & 215,073 & 215,073 & 215,073 & 211,071 & 200,721 & 14,352 \\
\hline R-squared & 0.086 & 0.087 & 0.349 & 0.079 & 0.069 & 0.268 \\
\hline Dependent Variable Mean & 0.071 & 0.071 & 0.222 & 0.068 & 0.060 & 0.219 \\
\hline
\end{tabular}

Notes: $* * * \mathrm{p}<0.01, * * \mathrm{p}<0.05, * \mathrm{p}<0.1$. All regressions include a constant term. Standard errors are in parentheses and clustered at the county level. This table reports the estimates from Equation (1) using daily COVID-19 deaths occurring between February 15, 2020 and April 23, 2020. In columns (1) and (2), we alter the definition of contagion we used to measure the speed of adoption of a safer-at-home order and/or non-essential business closure (NPI $)$. Specifically, we replace our original contagion threshold, which reflected the first day-to-day doubling of infections per capita in a given county to (1) the first day infections per capita exceeded the national average from January 21, 2020 to March 7, 2020 and (2) the county average infections per capita prior to NPI adoption, the results of which are found in columns (1) and (2), respectively. In column (3), we apply population weights to derive nationally representative estimates. In columns (4), (5), and (6), we experiment with using alternative samples to estimate Eq. (1). In column (4), we exclude New York from the analysis. In column (5), we exclude the entire Northeast region, which consists of Connecticut, Maine, Massachusetts, New Hampshire, Rhode Island, Vermont, New Jersey, New York, and Pennsylvania. In column (6), we focus exclusively on the Northeast region. 
Table 5: Exploring Main Mechanism -- Stemming Contagion and/or an Overwhelmed Healthcare System

\begin{tabular}{|c|c|c|c|c|c|c|}
\hline \multirow{2}{*}{\begin{tabular}{l|} 
Outcome \\
Column
\end{tabular}} & \multicolumn{3}{|c|}{ COVID-19 Infections per 100,000} & \multicolumn{3}{|c|}{ Non-COVID-19 Deaths per 100,000} \\
\hline & (1) & $(2)$ & (3) & (4) & (5) & (6) \\
\hline Sample & All Counties & Excluding NY & Excluding NE region & All Counties & Excluding NY & Excluding NE region \\
\hline Post $_{c t} \times N P I$ Speed $_{c}$ & $\begin{array}{c}-0.0329 * * * \\
(0.0024)\end{array}$ & $\begin{array}{c}-0.0310 * * * \\
(0.0023)\end{array}$ & $\begin{array}{c}-0.0276 * * * \\
(0.0022)\end{array}$ & $\begin{array}{c}-0.0415^{*} \\
(0.0229)\end{array}$ & $\begin{array}{l}-0.0333 \\
(0.0202)\end{array}$ & $\begin{array}{l}-0.0208 \\
(0.0168)\end{array}$ \\
\hline State-level tests per 100,000 & $\begin{array}{c}0.0028^{* * *} \\
(0.0005)\end{array}$ & $\begin{array}{c}0.0026^{* * *} \\
(0.0005)\end{array}$ & $\begin{array}{c}0.0011 * * \\
(0.0005)\end{array}$ & $\begin{array}{l}-0.0000 \\
(0.0000)\end{array}$ & $\begin{array}{l}-0.0000 \\
(0.0000)\end{array}$ & $\begin{array}{c}-0.0000 * \\
(0.0000)\end{array}$ \\
\hline Date Fixed-Effects & $\mathrm{Y}$ & $\mathrm{Y}$ & $\mathrm{Y}$ & $\mathrm{Y}$ & Y & Y \\
\hline County Fixed-Effects & $\mathrm{Y}$ & $\mathrm{Y}$ & $\mathrm{Y}$ & $\mathrm{Y}$ & Y & Y \\
\hline Observations & 215,073 & 211,071 & 200,721 & 561 & 550 & 462 \\
\hline R-squared & 0.124 & 0.110 & 0.093 & 0.801 & 0.855 & 0.920 \\
\hline Dependent Variable Mean & 1.651 & 1.578 & 1.444 & 12.082 & 12.342 & 12.439 \\
\hline
\end{tabular}

Notes: ${ }^{* * *} \mathrm{p}<0.01,{ }^{* *} \mathrm{p}<0.05,{ }^{*} \mathrm{p}<0.1$. All regressions include a constant term. Standard errors are in parentheses and clustered at the county level. 
Table 6: Heterogenous Effects of NPI Speed on COVID-19 Deaths per 100,000 Residents

\begin{tabular}{|c|c|c|c|c|c|c|}
\hline Column & (1) & (2) & (3) & (4) & (5) & (6) \\
\hline County Characteristic $\left(C C_{c}\right)$ & Majority Republican & \% over 65 & $\%$ Uninsured & \% Unemployed & \% below FPL & Comorbidity Index \\
\hline Post $_{c t} \times N P I$ Speed $_{c}$ & $\begin{array}{c}-0.0037^{* * *} \\
(0.0007)\end{array}$ & $\begin{array}{c}-0.0031 * * * \\
(0.0006)\end{array}$ & $\begin{array}{c}-0.0022 * * * \\
(0.0003)\end{array}$ & $\begin{array}{c}-0.0023^{* * *} \\
(0.0003)\end{array}$ & $\begin{array}{c}-0.0026 * * * \\
(0.0004)\end{array}$ & $\begin{array}{c}-0.0019 * * * \\
(0.0002)\end{array}$ \\
\hline Post $_{c t} \times N P I$ Speed $_{c} \times C C_{c}$ & $\begin{array}{c}0.0020 * * * \\
(0.0006)\end{array}$ & $\begin{array}{c}0.0001 * * \\
(0.0000)\end{array}$ & $\begin{array}{c}0.0000 \\
(0.0000)\end{array}$ & $\begin{array}{c}0.0002 \\
(0.0002)\end{array}$ & $\begin{array}{c}0.0001 \\
(0.0000)\end{array}$ & $\begin{array}{c}0.0001 \\
(0.0001)\end{array}$ \\
\hline Date Fixed-Effects & $\mathrm{Y}$ & $\mathrm{Y}$ & $\mathrm{Y}$ & $\mathrm{Y}$ & $\mathrm{Y}$ & $\mathrm{Y}$ \\
\hline County Fixed-Effects & $\mathrm{Y}$ & $\mathrm{Y}$ & $\mathrm{Y}$ & $\mathrm{Y}$ & $\mathrm{Y}$ & $\mathrm{Y}$ \\
\hline Observations & 213,141 & 215,073 & 215,004 & 215,004 & 215,004 & 215,073 \\
\hline R-squared & 0.087 & 0.087 & 0.087 & 0.087 & 0.087 & 0.087 \\
\hline Dependent Variable Mean & 0.072 & 0.071 & 0.071 & 0.071 & 0.071 & 0.071 \\
\hline
\end{tabular}

Notes: $* * * \mathrm{p}<0.01, * * \mathrm{p}<0.05, * \mathrm{p}<0.1$. All regressions include a constant term. Standard errors are in parentheses and clustered at the county level. Observations vary across specifications due to missing data. Column (1) uses information from 3,089 because 28 were missing information on election returns. Columns (3), (4), and (5) use information from 3,116 counties because one county was missing information on the number of residents without health insurance, unemployed, or living below the federal poverty line. 
Figure 1: Daily COVID-19 Mortality by Non-Pharmaceutical Intervention Timing

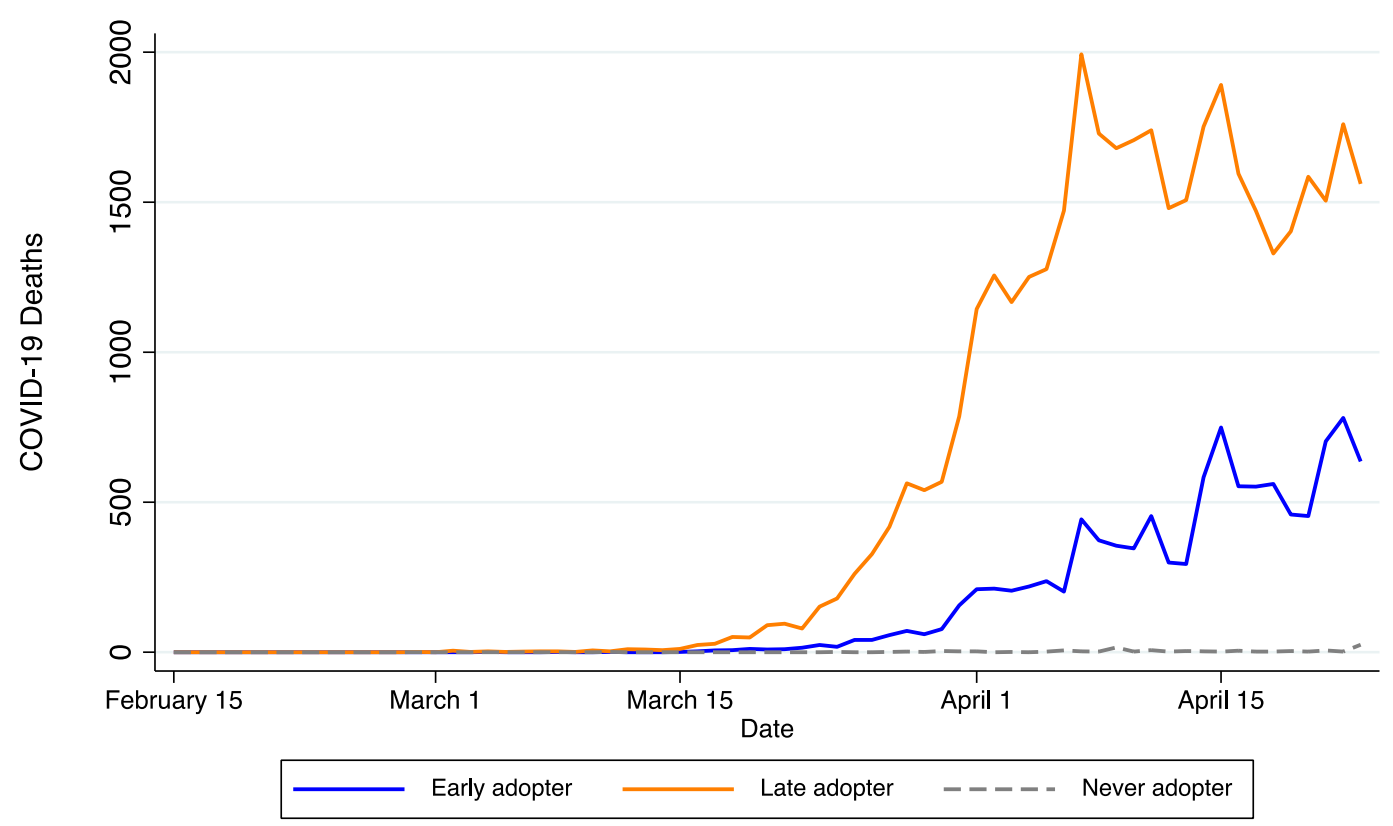

Figure 2: Daily COVID-19 Mortality Rates by Non-Pharmaceutical Intervention Timing

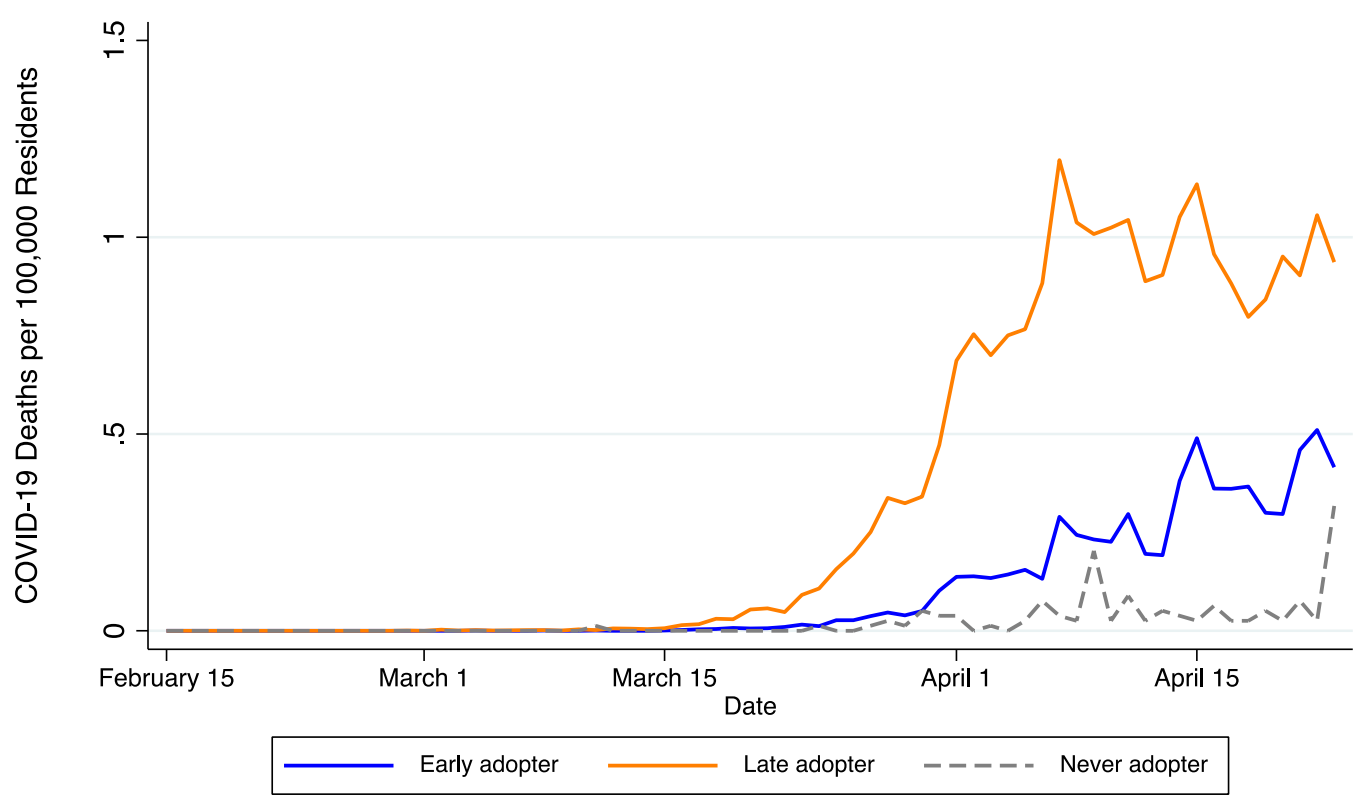

Notes: Early adopters include counties with safer at home and/or business closure policies in place prior to the first day-to-day doubling of infections per capita. Late adopters include counties that adopted an NPI after the first day-to-day infection doubling. Never adopters include counties that did not have a safer at home or business closure policy in place anytime between February 15, 2020 and April 23, 2020. 
Figure 3: Geographic Variation in Adoption of Non-Pharmaceutical Interventions As of March 20, 2020

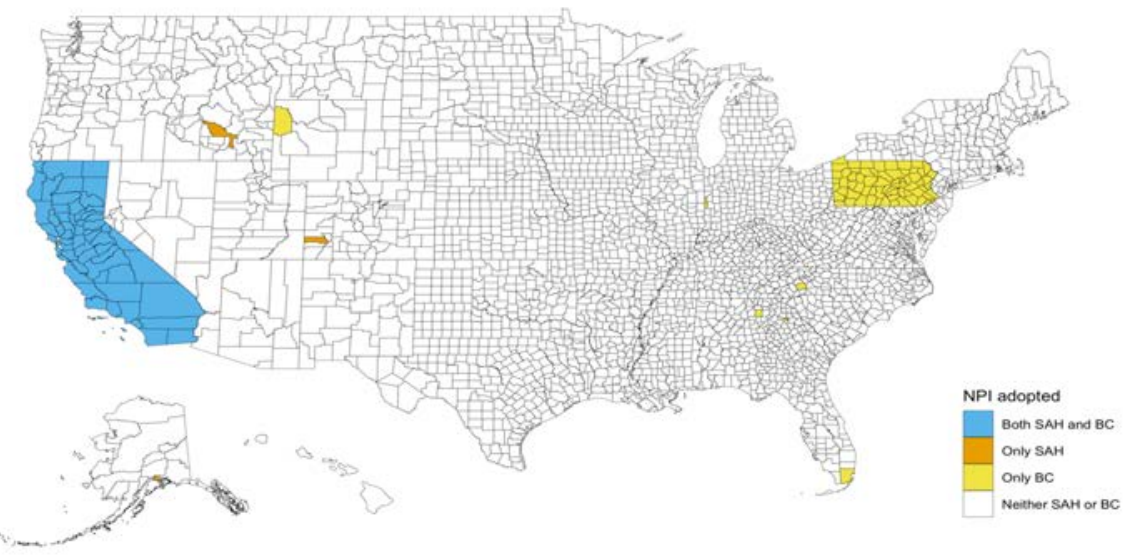

As of March 30, 2020

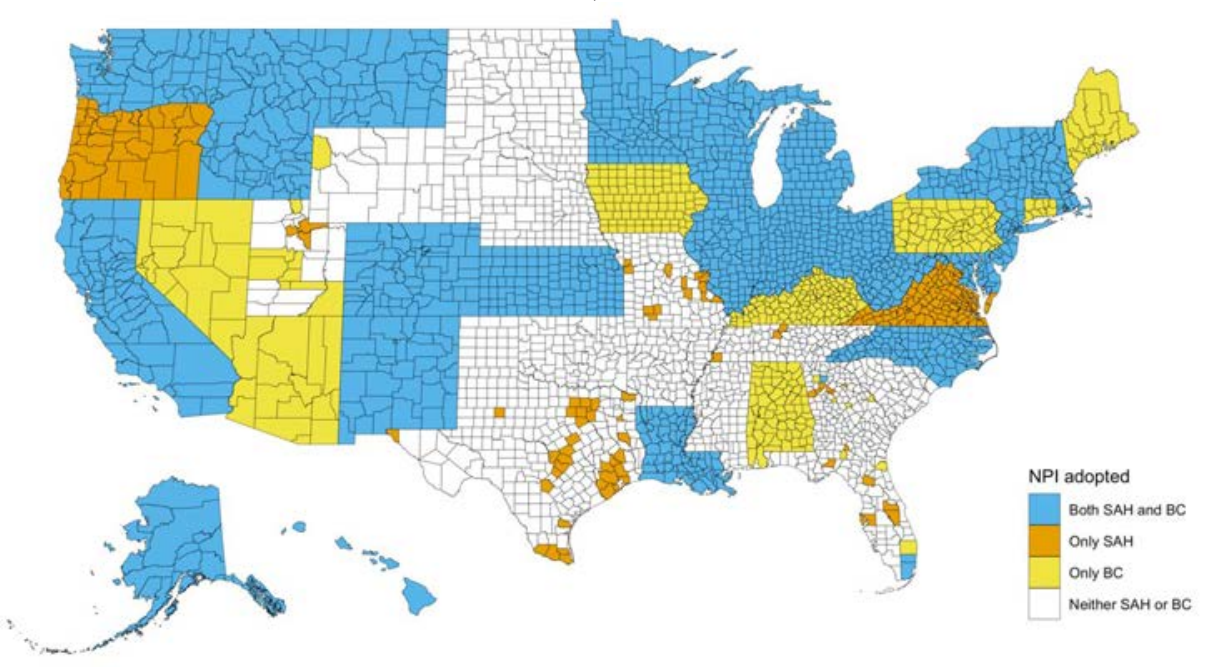

Source: NACo and Boston University SPH COVID-19 U.S. State Policy Database

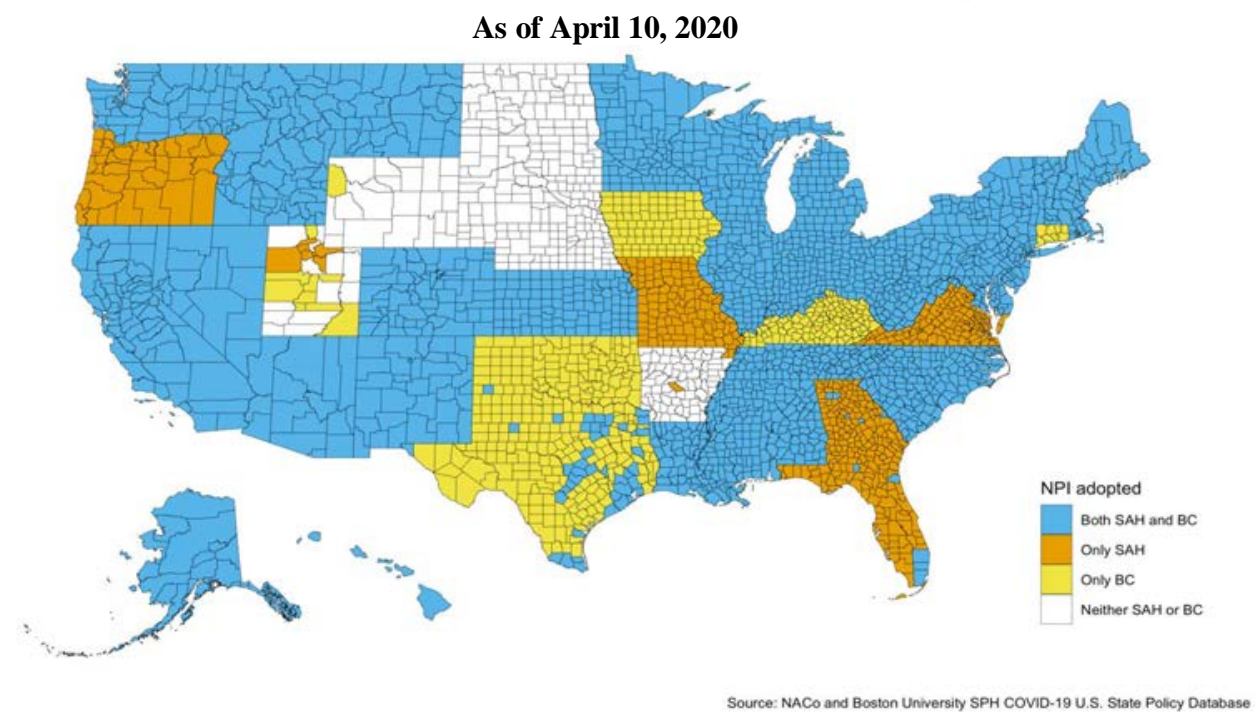


Figure 4: Event Study

Non-Pharmaceutical Invention Effects on COVID-19 Deaths per Capita

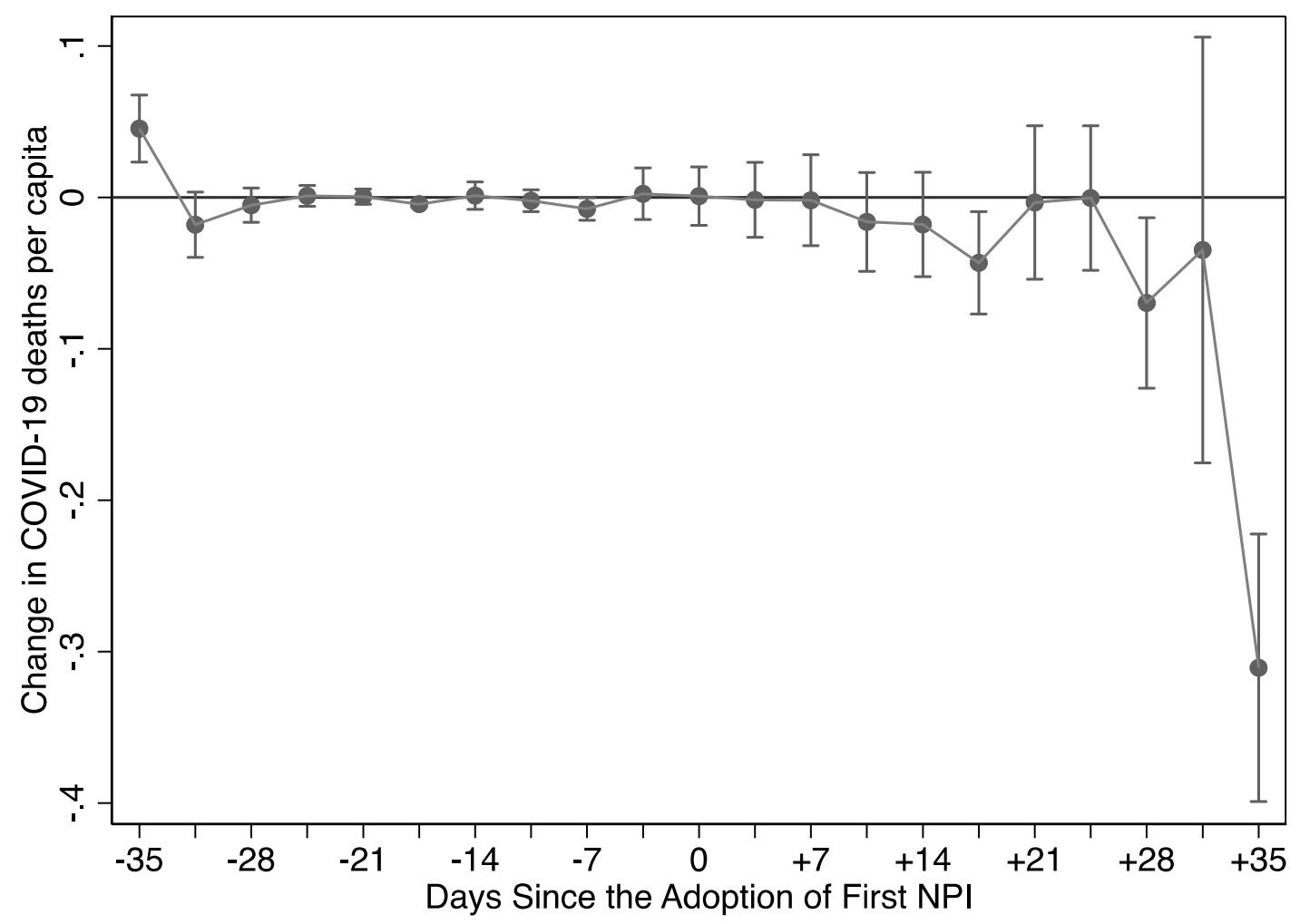

Notes: Figure plots the $\beta_{t}$ coefficients from Eq. 2, including controls for state-level testing and residential mobility. Bands represent 95\% confidence intervals for each estimate. 


\section{Appendix}

Table A: Robustness Checks - Impact of NPI Speed on COVID-19 Deaths per 100,000 Residents

\begin{tabular}{|c|c|c|c|c|c|c|}
\hline \multirow{2}{*}{$\begin{array}{l}\text { Robustness Check } \\
\text { Column }\end{array}$} & \multicolumn{2}{|c|}{ Alternative Contagion Threshold } & \multirow{2}{*}{$\begin{array}{c}\text { Alternative Weighting } \\
\text { (3) }\end{array}$} & \multicolumn{3}{|c|}{ Alternative Samples } \\
\hline & (1) & $(2)$ & & (4) & (5) & (6) \\
\hline Model Specification & $\begin{array}{c}\text { Pre-NPI National } \\
\text { Average }\end{array}$ & $\begin{array}{c}\text { Pre-NPI County } \\
\text { Average }\end{array}$ & Population weighted & $\begin{array}{c}\text { Excluding } \\
\text { NY }\end{array}$ & $\begin{array}{l}\text { Excluding } \\
\text { NE Region }\end{array}$ & $\begin{array}{l}\text { Only the } \\
\text { NE Region }\end{array}$ \\
\hline Post $_{c t} \times$ BC Speed S $_{c}$ & $\begin{array}{c}-0.0014^{* * *} \\
(0.0002)\end{array}$ & $\begin{array}{c}-0.0017^{* * *} \\
(0.0004)\end{array}$ & $\begin{array}{c}-0.0068 * * \\
(0.0032)\end{array}$ & $\begin{array}{c}-0.0015^{* * *} \\
(0.0002)\end{array}$ & $\begin{array}{c}-0.0013^{* * *} \\
(0.0002)\end{array}$ & $\begin{array}{c}-0.0094 * * * \\
(0.0020)\end{array}$ \\
\hline Post $_{c t} \times S A H$ Speed $_{c}$ & $\begin{array}{c}-0.0005 * * \\
(0.0002)\end{array}$ & $\begin{array}{c}-0.0029 * * * \\
(0.0006)\end{array}$ & $\begin{array}{c}-0.0095 * * \\
(0.0043)\end{array}$ & $\begin{array}{c}-0.0007 * * * \\
(0.0002)\end{array}$ & $\begin{array}{c}-0.0004 * * \\
(0.0002)\end{array}$ & $\begin{array}{c}-0.0102 * * * \\
(0.0023)\end{array}$ \\
\hline Date Fixed-Effects & $\mathrm{Y}$ & $\mathrm{Y}$ & $\mathrm{Y}$ & $\mathrm{Y}$ & $\mathrm{Y}$ & $\mathrm{Y}$ \\
\hline County Fixed-Effects & $\mathrm{Y}$ & $\mathrm{Y}$ & $\mathrm{Y}$ & $\mathrm{Y}$ & $\mathrm{Y}$ & $\mathrm{Y}$ \\
\hline Observations & 215,073 & 215,073 & 215,073 & 211,071 & 200,721 & 14,352 \\
\hline R-squared & 0.087 & 0.087 & 0.351 & 0.080 & 0.070 & 0.275 \\
\hline Dependent Variable Mean & 0.071 & 0.071 & 0.222 & 0.068 & 0.060 & 0.219 \\
\hline
\end{tabular}

Notes: $* * * \mathrm{p}<0.01, * * \mathrm{p}<0.05, * \mathrm{p}<0.1$. All regressions include a constant term. Standard errors are in parentheses and clustered at the county level. This table reports the estimates from Equation (1) using daily COVID-19 deaths occurring between February 15, 2020 and April 23, 2020. In columns (1) and (2), we alter the definition of contagion we used to measure the speed of adoption of safer-at-home orders $\left(S A H_{c}\right)$ and non-essential business closures $\left(B C_{c}\right)$. Specifically, we replace our original contagion threshold, which reflected the first day-to-day doubling of infections per capita in a given county to (1) the first day infections per capita exceeded the national average from January 21, 2020 to March 7, 2020 and (2) the county average infections per capita prior to NPI adoption, the results of which are found in columns (1) and (2), respectively. In column (3), we apply population weights to derive nationally representative estimates. In columns (4), (5), and (6), we experiment with using alternative samples to estimate Eq. (1). In column (4), we exclude New York from the analysis. In column (5), we exclude the entire Northeast region, which consists of Connecticut, Maine, Massachusetts, New Hampshire, Rhode Island, Vermont, New Jersey, New York, and Pennsylvania. In column (6), we focus exclusively on the Northeast region. 
Table B: Exploring Main Mechanism: Stemming Contagion

\begin{tabular}{|c|c|c|c|c|c|c|}
\hline \multirow{2}{*}{$\begin{array}{l}\text { Outcome } \\
\text { Column }\end{array}$} & \multicolumn{3}{|c|}{ COVID-19 Infections per 100,000} & \multicolumn{3}{|c|}{ Non-COVID-19 Deaths per 100,000} \\
\hline & (1) & (2) & (3) & (4) & (5) & (6) \\
\hline Sample & All Counties & Excluding NY & Excluding NE Region & All Counties & Excluding NY & Excluding NE Region \\
\hline Post $_{c t} \times$ BC Speed ${ }_{c}$ & $\begin{array}{c}-0.0237^{* * *} \\
(0.0019)\end{array}$ & $\begin{array}{c}-0.0224^{* * *} \\
(0.0018)\end{array}$ & $\begin{array}{c}-0.0214^{* * *} \\
(0.0019)\end{array}$ & $\begin{array}{c}0.0056 \\
(0.0306)\end{array}$ & $\begin{array}{l}-0.0006 \\
(0.0170)\end{array}$ & $\begin{array}{l}-0.0070 \\
(0.0167)\end{array}$ \\
\hline Post $_{c t} \times S A H$ Speed $_{c}$ & $\begin{array}{c}-0.0164^{* * *} \\
(0.0020)\end{array}$ & $\begin{array}{c}-0.0149 * * * \\
(0.0018)\end{array}$ & $\begin{array}{c}-0.0102 * * * \\
(0.0017)\end{array}$ & $\begin{array}{l}-0.0127 \\
(0.0342)\end{array}$ & $\begin{array}{l}-0.0237 \\
(0.0232)\end{array}$ & $\begin{array}{c}0.0052 \\
(0.0152)\end{array}$ \\
\hline State-level tests per 100,000 & $\begin{array}{c}0.0030 * * * \\
(0.0005)\end{array}$ & $\begin{array}{c}0.0029 * * * \\
(0.0005)\end{array}$ & $\begin{array}{c}0.0013^{* * *} \\
(0.0005)\end{array}$ & $\begin{array}{l}-0.0000 \\
(0.0000)\end{array}$ & $\begin{array}{l}-0.0000 \\
(0.0000)\end{array}$ & $\begin{array}{l}-0.0000 * \\
(0.0000)\end{array}$ \\
\hline Date Fixed-Effects & $\mathrm{Y}$ & $\mathrm{Y}$ & $\mathrm{Y}$ & $\mathrm{Y}$ & $\mathrm{Y}$ & $\mathrm{Y}$ \\
\hline County Fixed-Effects & $\mathrm{Y}$ & $\mathrm{Y}$ & $\mathrm{Y}$ & $\mathrm{Y}$ & $\mathrm{Y}$ & $\mathrm{Y}$ \\
\hline Observations & 215,073 & 211,071 & 200,721 & 561 & 550 & 462 \\
\hline R-squared & 0.124 & 0.110 & 0.093 & 0.800 & 0.854 & 0.919 \\
\hline Dependent Variable Mean & 1.651 & 1.578 & 1.444 & 12.082 & 12.342 & 12.439 \\
\hline
\end{tabular}

Notes: *** $\mathrm{p}<0.01, * * \mathrm{p}<0.05, * \mathrm{p}<0.1$. All regressions include a constant term. Standard errors are in parentheses and clustered at the county level. 
Table C: Impact of NPI Speed on COVID-19 Deaths per 100,000 Residents Using Restricted Sample

\begin{tabular}{|c|c|c|}
\hline Model Specification & (1) & (2) \\
\hline \multicolumn{3}{|c|}{ Panel A: Consolidated NPI speed } \\
\hline Post $_{c t} \times N P I$ speed $_{c}$ & $\begin{array}{c}-0.0022 * * * \\
(0.0002)\end{array}$ & $\begin{array}{c}-0.0024 * * * \\
(0.0002)\end{array}$ \\
\hline State test results per 100,000 & & $\begin{array}{c}0.0003^{* * * *} \\
(0.0000)\end{array}$ \\
\hline Observations & 141,480 & 141,480 \\
\hline R-squared & 0.125 & 0.132 \\
\hline Dependent Variable Mean & 0.101 & 0.101 \\
\hline \multicolumn{3}{|c|}{ Panel B: Disaggregated NPI speeds } \\
\hline 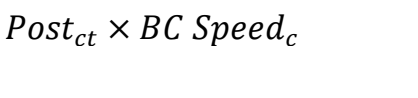 & $\begin{array}{c}-0.0020 * * * \\
(0.0002)\end{array}$ & $\begin{array}{c}-0.0015^{* * *} \\
(0.0002)\end{array}$ \\
\hline Post $_{c t} \times$ SAH Speed $_{c}$ & $\begin{array}{c}-0.0010 * * * \\
(0.0002)\end{array}$ & $\begin{array}{c}-0.0012 * * * \\
(0.0002)\end{array}$ \\
\hline State test results per 100,000 & & $\begin{array}{c}0.0003^{* * *} \\
(0.0000)\end{array}$ \\
\hline Observations & 141,480 & 141,480 \\
\hline R-squared & 0.126 & 0.132 \\
\hline Dependent Variable Mean & 0.101 & 0.101 \\
\hline \multicolumn{3}{|l|}{ For all specifications above: } \\
\hline Date Fixed-Effects & $\mathrm{Y}$ & $\mathrm{Y}$ \\
\hline County Fixed-Effects & $\mathrm{Y}$ & $\mathrm{Y}$ \\
\hline
\end{tabular}

Notes: ${ }^{* *} \mathrm{p}<0.01,{ }^{* *} \mathrm{p}<0.05,{ }^{*} \mathrm{p}<0.1$. All regressions include a constant term. Standard errors are in parentheses and clustered at the county level. This table reports the estimates from Equation (1) using daily COVID-19 deaths occurring between March 1, 2020 to April 23, 2020 for the 2,260 counties with mobility data. The specification in column (1) only includes date and county fixed effects, while column (2) controls for state-level testing. 